\title{
Unilateral Protostylid on Buccal Surface of Permanent Maxillary First Molar: A Rare Finding
}

\author{
Ghazala Hassan $^{1}$ \\ BDS \\ Sarah Ghafoor ${ }^{2} \quad$ BDS, PhD
}

\begin{abstract}
Human dentition either primary or permanent exhibits a number of developmental morphological variations ranging from mild alterations in tooth shape to well developed supernumerary cusp. These genetic malformations may present as an isolated finding or as a part of a syndrome. A protostylid is an uncommon anomaly which presents as a supernumerary or accessory cusp located on the mesial half of the buccal surface on the maxillary or mandibular molars which seldom pose problems to the patient. As its prevalence varies with ethnic diversity, it is a frequent object for anthropological studies. A 31 year old Pakistani female presented with a complaint of pain in right mandibular quadrant. Complete intraoral examination revealed a supernumerary cusp on the right permanent maxillary first molar as an incidental finding. No syndromic association was found.

KEY WORDS: Extra cusp; maxillary molar; morphological variations; protostylid; parastyle.

HOW TO CITE: Hassan G, Ghafoor S. Unilateral protostylid on buccal surface of permanent maxillary first molar: a rare finding. J Pak Dent Assoc 2018;27(3):157-59.

DOI: https://doi.org/10.25301/JPDA.273.157

Received: 29 December 2017, Accepted: 19 April 2018
\end{abstract}

\section{INTRODUCTION}

$\mathrm{T}$ ooth development follows a series of reciprocally between the ectodermally-derived oral epithelium and neural crest cells-derived dental mesenchyme. A number of biological molecules released from these tissues maintain these reciprocal interactions. These secreted signaling molecules belong to major signaling families including Fibroblast growth factor (FGF), Transforming growth factor (TGF- $\beta$ ), Wingless (WNT) and Hedgehog (HH). Typically, development of placode relies on signals from all these four major families. These molecules then control various cellular events via interactions with transcription factors such as the members of Msx, Pax and Runx families. ${ }^{1}$

Developmental abnormalities affecting either deciduous or permanent dentition can exhibit in the form of changes in the crown shape, size or number of cusps or roots. These may affect one or more maxillary or mandibular teeth depending upon the magnitude of developmental disturbance. Developmental morphological variations such as gemination, fusion, taurodontism, concrescence, enamel pearl and supernumerary cusp have been reported. ${ }^{2}$

Dental traits which are not commonly seen in humans

1. M.Phil Student Part II, Department of Oral Biology, University of Health Sciences, Lahore, Pakistan

2. Assistant Professor, Department of Oral Biology, University of Health Sciences, Lahore, Pakistan.

Corresponding author: "Dr. Sarah Ghafoor”<sarahghafoor@uhs.edu.pk> include protostylid, Entoconulid (Cusp 6) \& Metaconulid (Cusp 7) on permanent molars and abnormal triangular morphology of deciduous molars have been reported. ${ }^{1}$ These anomalies are less frequent yet not uncommon. The purpose of this case report is to highlight finding of rare dental traits in human dentition as no data is available regarding such anomalies in Pakistani population.

\section{CASE REPORT}

A 31 year old female presented to the outpatient dental department of University of Health Sciences, Lahore, Pakistan in March, 2017 with the complaint of pain in right mandibular quadrant.

The patient reported with no history of any systemic illness. Complete intra-oral examination revealed poor oral hygiene status along with grossly carious right mandibular first molar. It also showed the presence of supernumerary cusp on the buccal aspect of the right maxillary first molar as an incidental finding. As a result the periodontium of the tooth was compromised and had gingival recession and bone loss with visible sub-gingival calculus and exposed root Figure 1.

Peri-apical X-ray of right maxillary first molar revealed an additional cusp over the mesio-buccal cusp. Other features include generalized inter-dental bone loss Figure 2.

The patient was not followed up. An informed consent regarding the publication of the scientific data was taken 


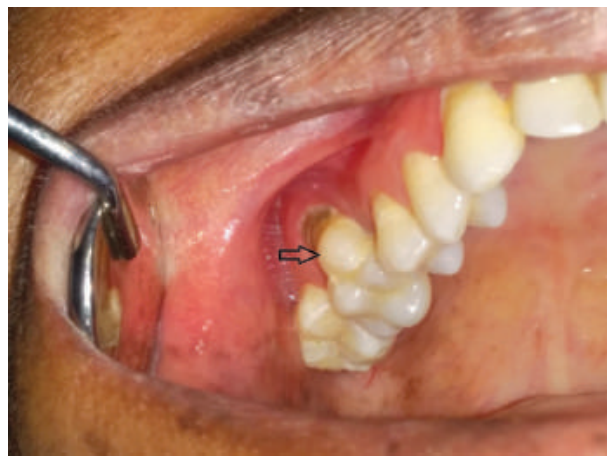

Figure 1: Intra oral finding include supernumerary cusp on the buccal aspect of the right maxillary first molar indicated by black arrow.

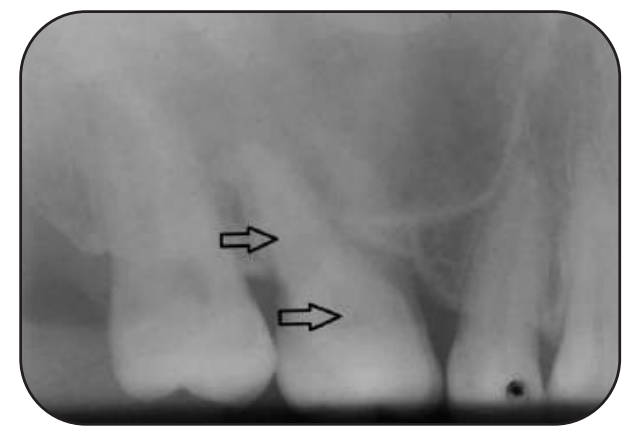

Figure 2: Peri-apical X-ray of right maxillary first molar revealed an additional cusp over the mesio-buccal cusp along with a well-developed supernumerary root (Black arrow).

from the patient. An ethical approval from the Ethical Review Board of University of Health Sciences was also taken.

\section{DISCUSSION}

Elevations or a mold on the crown portion of the tooth which make up a divisional part of the occlusal surface is denoted as a cusp. Supernumerary or accessory cusps are the extra number of cusps that occur can on the surface of the tooth. Accessory cusps can occur either as dental anomalies (dens evaginatus) or as normal anatomical variations (protostylid, parastyle, and Cusp of Carabelli). ${ }^{3}$ These morphological variants manifest in low frequencies in the human populations and also represent racial and regional variations. There are no such reports published in Pakistani population regarding prevelance of these developmental anomalies.

"Paramolar Tubercle" is any stylar anomalous cusp or prominence on the outer surface of both maxillary and mandibular premolar and molars. ${ }^{3}$ It seldom poses any dental problem to the patient due to its location. In 1945, Dahlberg introduced a specific paleontological nomenclature for paramolar tubercle referring to this structure as parastyle when an extra cusp is found in the maxillary molars and as protostylid when its present in the mandibular molars. ${ }^{4}$ It is also called "Mesiobuccal edge prominencies".

Paramolar tubercle vary with respect to size and shape. It may present as anything ranging from a mere eminence on the outer surface, distinguished from rest of the tooth by a fossa or a groove, to a well-developed lobulated cusp, separated by a constriction and having the appearance of a fused supernumerary tooth. This lobulated structure is often found in association with a rudimentary or well-developed root. ${ }^{5,6}$ It is not always necessary that these tubercles contain pulp tissue. Root canals configuration of the tubercle range from canal connected to the other canals ${ }^{7}$ or may present as an isolated canal. ${ }^{8}$ Radiographic findings include a dentin core is covered by enamel. If tubercule is worn to point of pulpal exposure or fracture, pulpal necrosis may occur. ${ }^{4}$

The cause of supernumerary cusp formation or abberant shape is multi-factorial. However, it is believed that overactivity PAX and MSX genes in the dental lamina lead to the abnormal shape of the teeth. ${ }^{3}$ Also mutations in Eda and Edar can lead to mishappentooth. Over-expression of Eda A1 could lead to extra cusp and tooth formation. Mouse mutants of Eda (Tabby) have abnormal shape of crown.$^{9}$ Para-molar tubercles provide insight into dental evolution and development.

Paramolar tubercles have long been recognized as nonmetric dental traits (NMDT) which are the structural features manifested within certain biological and geographical domains. Ethnic and racial variations may play an important role in its occurrence. The occurrence of paramolar tubercle is relatively uncommon. Though there is very little information about racial differences in the frequencies of paramolar tubercles, primarily because of their low occurrence, none the less they should not be classified as anomalous structure since they are normal morphological features of the dentition. They usually presents unilaterally in the permanent dentition. Its frequency varies different populations. The prevalence of protostylid varies in different ethnic groups, like $18.5 \%$ in Japanese people, $37.5 \%$ in Chinese population, while $5.4 \%$ in Colombian population. ${ }^{10}$

The paramolar tubercles are clinically relevant as they affect the treatment regimens and its related problems in many dental specialities. These superstructures are potent areas for plaque adherence as maintenance of oral hygiene in these areas is difficult and recurrence of dental caries, gingivitis, and localized periodontitis is more common. As observed in our case, the tubercle that projects from the tooth or the alveolus causes gingival regression leading to a decreased buccal alveolar bone level resulting in deterioration of the surrounding periodontal tissue. These tubercles even 
pose problem in the preparation of a tooth for the setting of an artificial crown. ${ }^{11}$

\section{CONCLUSION}

Protostylid or parastyle is a developmental tooth anomaly that has a rare occurance in human population. It has evident clinical implications which distinguish it markedly from teeth with normal morphological features. This manuscript encourages the dentists to report the cases of unusual morphological characteristics and to design the prevalence population studies in order to determine the NMDT's frequency and variability among different ethnic populations. Thus, contributing to the construction of world dental anthropological data. ${ }^{11}$

\section{ACKNOWLEDGEMENTS}

We would like to acknowledge Higher Education Commission (HEC) and University of Health Sciences (UHS) library for the facility of E-library and online search of appropriate content.

Disclaimer: We confirm that this work is original and has not been published elsewhere, nor is it currently under consideration for publication elsewhere.

\section{CONFLICT OF INTEREST}

The authors declare no conflict of interest.

\section{REFERENCES}

1. Jussila M, Thesleff I. Signaling networks regulating tooth organogenesis and regeneration, and the specification of dental mesenchymal and epithelial cell lineages. Cold Spring Harbor perspectives in biology. 2012;4(4):a008425.

https://doi.org/10.1101/cshperspect.a008425
2. Turner RA, Harris EF. Maxillary second premolars with paramolar tubercles. Dental Anthropology. 2004;17(3):75-8.

3. Desai VD, Sadnani H, Kumar SM, Pratik P. Protostylid: As never reported before! A unique case with variation. Journal of Indian Academy of Oral Medicine and Radiology. 2016;28(1):57. https://doi.org/10.4103/0972-1363.189982

4. Dahlberg AA. The evolutionary significance of the protostylid. American journal of physical anthropology. 1950;8(1):15-26. https://doi.org/10.1002/ajpa.1330080110

5. Friedman S, Stabholz A, Rotstein I. Endodontic management of molars with developmental anomalies. International endodontic journal. 1986;19(6):267-76

https://doi.org/10.1111/j.1365-2591.1986.tb00490.x

6. Magalee R, Kramer S. The paramolar tubercle: a morphological anomaly with clinical considerations. The New York state dental journal. 1984;50(9):564, 6-, 6.

7. Zidan O, El-Deeb M. Restorative and endodontic management of an anomalous mandibular molar. Quintessence International. 1991;22(3).

8. Baghdady MT, Pharoah MJ, Regehr G, Lam EW, Woods NN. The role of basic sciences in diagnostic oral radiology. Journal of dental education. 2009;73(10):1187-93.

9. Thesleff I. The genetic basis of tooth development and dental defects. American Journal of Medical Genetics Part A. 2006;140(23):2530-5. https://doi.org/10.1002/ajmg.a.31360

10. Baby TK, Sunil S, Babu SS. Nonmetric traits of permanent posterior teeth in Kerala population: A forensic overview. Journal of oral and maxillofacial pathology: JOMFP. 2017;21(2):301. https://doi.org/10.4103/jomfp.JOMFP_21_17

11. Moreno S, Reyes MP, Moreno F. Cusp expression of protostylid in deciduous and permanent molars. Journal of forensic dental sciences. 2016;8(3):155.

https://doi.org/10.4103/0975-1475.195108 